\title{
An Empirical Study on the Impact of Government Subsidies on the Financial Performance of Agricultural Listed Companies
}

\author{
Qian Min ${ }^{1}$, Han Keying ${ }^{1, *}$ \\ ${ }^{1}$ School of Management, Xi'an University of Science and Technology, Xi'an, Shaanxi \\ *Corresponding author.Email:969401691@qq.com
}

\begin{abstract}
The No. 1 Central Document has always focused on agriculture, and the government has made agriculture the top priority of its work. To a certain extent, listed agriculture-related companies represent the development of my country's agricultural economy and lead the development of my country's agricultural economy. Government subsidies are one of the important policy measures to promote industrial development. The amount of government subsidy funds paid by the Chinese government to various industries has been increasing year by year, which has effectively promoted the development of related industries. The policy effects of government subsidies have also been concerned by all sectors of society. This article selects agricultural-related listed companies among the 181 Shanghai and Shenzhen A-share listed companies from 2015 to 2019 as the research sample to empirically study the impact of government subsidies on corporate financial performance, and find that government subsidies can effectively improve corporate financial performance in the current period At the same time, government subsidies can also improve the financial performance of companies that are lagging behind. However, government subsidies related to income have a negative effect on corporate financial performance, and government subsidies related to assets have a positive effect on corporate financial performance. Based on this, this article puts forward suggestions for optimizing government subsidies.
\end{abstract}

Keywords: agriculture-related listed companies, company performance, government subsidies

\section{政府补助对涉农上市公司财务绩效影响实证研究}

\author{
钱敏 ${ }^{1}$ 韩可颖 ${ }^{1, *}$
}

\author{
${ }^{I}$ 西安科技大学管理学院, 西安, 陕西 \\ *969401691@qq.com
}

\begin{abstract}
摘要
中央一号文件一直聚焦农业, 政府将农业作为工作的重中之重, 涉农上市公司一定程度上在代表了我国农业经 济的发展, 引领着我国农业经济的发展。政府补助是促进产业发展的重要政策手段之一，我国政府对各个行业 的政府补助资金支出数额在逐年增加, 有力地促进了相关产业的发展。政府补助的政策效果也一直受到社会各 界的关注。本文选择 2015-2019 年间的 181 家沪深两市 A 股上市公司中的涉农上市公司为研究样本, 实证研究 政府补助对企业财务绩效的影响，结果发现，政府补助能够有效提高当期企业财务绩效，同时，政府补助也能 提高滞后一期的企业财务绩效，但与收益相关的政府补助对企业财务绩效呈现消极作用，与资产相关的政府补 助对企业财务绩效具有积极作用。基于此，本文提出了优化政府补助的建议。
\end{abstract}

关键词：涉农上市公司，公司绩效，政府补助 


\section{1. 引言}

我国拥有着悠久的农耕文明, 是一个传统的农业 大国。农业是提供支撑国民经济建设与发展的基础产 业, 关系着我国国民经济的命脉, 是社会经济发展稳 定的根基, 历年来受到了党和政府的高度重视。根据 国家统计局的数据, 2019 年我国第一产业增加值 70466.7 亿元, 占国内生产总值的 7.11\%, 第一产业 就业人员达到 11475 万人，占就业人员总数 $25.11 \%$ 的。农业经济的发展, 将直接对国民经济的发展与社 会稳定产生重要影响。2020 年的中央一号文件中再 度聚焦 “三农”，这是自 2004 年以来，中央一号文 件连续 17 年聚焦 “三农” 问题, 凸显了 “三农” 问 题的重要性, 表达出政府将农业作为工作的重中之重 来开展的决心。

\section{2. 文献综述}

通过对文献研读与整理发现, 上个世纪始, 国外 学者对政府补助的动因、影响因素以及政府补助与财 务绩效之间的关系进行了研究。

政府补助的动机研究。Bernini等 (2011) ${ }^{[1]}$ 通 过意大利政府的 “448 法案” 发现员工较多的企业更 容易获得政府补助。Guth等 (2017) ${ }^{[2]}$ 研究发现农业 企业获得政府补助后, 为社会提供更多的社会公共资 源。柴源 (2018) ${ }^{[3]}$ 研究近十年的上市公司数据, 发 现政府补贴与企业创新绩效正相关关系。

政府补助的影响因素研究。Attia等 (2016) ${ }^{[4]}$ 研究近几年突尼斯公司数据, 发现政府补助倾向于有 政治关联度的企业。步丹璐和狄灵瑜（2017） ${ }^{[5]}$ 通过 2007-2014 年上市公司数据, 发现国有企业更容易获 取政府补助。

政府补助对企业绩效影响的研究。Tundis等 (2017) ${ }^{[6]}$ 研究意大利的政府补助对酒店业的绩效有 积极促进作用。Zhang、 $\mathrm{Li}$ 等 (2014) ${ }^{[7]}$ 政府发放的 补助不受时间期限的影响, 都能够提高企业绩效。 Dizon-Ross等（2017） ${ }^{[8]}$ 发现政府财政补贴资金不能 对企业的绩效有实质性的影响。杨晔等 $(2015)^{[9]}$ 研究 发现政府补助能够降低研发风险, 对企业经营绩效有 积极作用。王新红等 (2019) ${ }^{[10]}$ 对 2012-2016 年制造 业数据研究, 发现政府补助增加会帮助企业提高经营 业绩，但对国有企业并无影响。景曼诗等（2018） ${ }^{[11]}$ 研究发现政府补助对不同行业的绩效影响无促进作 用。秦莉等 (2019) ${ }^{[12]}$ 研究近十年电力行业数据, 发 现政府补助对企业绩效呈现负向效果。

\section{3. 理论分析与研究假设}

政府补助有无偿性、附条件的特征，这是政府通 过货币性或非货币性的手段所给予企业的帮助, 期望 通过资金上的帮助能够帮助企业渡过困难。本文将利 用本文将利用涉农上市公司数据来实证研究政府补 助对企业财务绩效的影响。提出假设 1: 涉农上市企
业的当期政府补助有助于提升当期财务绩效。

当政府补助用于推出新产品等周期长的项目时, 政府补助对于企业财务业绩的提升不能在当期显现 出来。所以本文初步判断涉农企业收到政府补助对企 业财务绩效的正向促进作用并有滞后性的。提出假设 2 : 涉农上市企业的政府补助对企业财务绩效具有正 向促进作用且存在着一定的滞后性。

与收益相关的政府补助计入利润表, 大多是已发 生与费用有关的补助, 对企业当期利润有影响, 这些 补助提高了涉农上市公司抵抗财务风险的能力。提出 假设 3: 与收益相关的政府补助对涉农上市企业财务 绩效有积极作用。

与资产相关的政府补助，是指政府对企业购买、 构建或者以其他形式形成的资产予以的补助, 计入递 延收益, 对未来利润产生影响。提出假设 4: 与资产 相关的政府补助对涉农上市企业财务绩效有积极作 用。

\section{4. 研究设计}

\section{1 数据来源}

本文以 2015一2019 年沪深A股上市公司为研究 样本, 按照证监会 2012 版行业分类标准为依据, 对 涉农上市企业进行分类篎选。同时按照以下标准剔除: 剔除掉ST或*ST涉农上市企业; 剔除变量数据缺失、 披露不完善企业; 只保留发行 A股的企业。经过篎选 得到涉农行业的样本上市公司总数 181 家, 共计 905 个样本数据。数据来自国泰安以及Wind数据库, 数据 分析软件为 SPSS26.0。

\section{2 变量定义}

本文引入了三类变量: 被解释变量、解释变量以 及控制变量。

(1) 被解释变量: 通过对流动比率、速动比率、 现金比率、毛利率、每股收益、总资产周转率、流动 资产周转率、总资产报酬率、营业收入增长率、资本 累计率这 10 个财务指标进行因子分析, 得出企业绩 效的综合指标, 用Y来表示。

（2）解释变量: 政府补助（GOV）、上一年的政 府补助 (GOVt-1)、与收益相关的政府补助 (GOVsy)、 与资产相关的政府补助 (GOVzc)

(3) 控制变量: 产权性质 (OWN)、企业规模 (SIZE)、 资产负债率 (LEV)

研究变量定义表, 如下表所示: 
表 1 研究变量定义表

\begin{tabular}{|c|c|c|c|}
\hline $\begin{array}{l}\text { 分 } \\
\text { 类 }\end{array}$ & 变量类型 & $\begin{array}{c}\text { 变量符 } \\
\text { 号 }\end{array}$ & 计算方法 \\
\hline \multirow{10}{*}{$\begin{array}{l}\text { 被 } \\
\text { 解 } \\
\text { 释 } \\
\text { 变 } \\
\text { 量 }\end{array}$} & 流动比率 & X1 & $\begin{array}{c}\text { 期末流动资产/期末 } \\
\text { 流动负债 }\end{array}$ \\
\hline & 速动比率 & X2 & $\begin{array}{l}\text { （期末流动资产-存 } \\
\text { 货）/期末流动负债 }\end{array}$ \\
\hline & 现金比率 & X3 & $\begin{array}{l}\text { （货币资金+有价证 } \\
\text { 券）/期末流动负债 }\end{array}$ \\
\hline & 毛利率 & X4 & $\begin{array}{c}\text { (营业收入-营业成 } \\
\text { 本)/营业收入 }\end{array}$ \\
\hline & 每股收益 & X5 & 净利润/期末总股本 \\
\hline & 总资产周转率 & X6 & $\begin{array}{c}\text { 营业收入/总资产期 } \\
\text { 末总额 }\end{array}$ \\
\hline & $\begin{array}{c}\text { 流动资产周转 } \\
\text { 率 }\end{array}$ & X7 & $\begin{array}{c}\text { 营业收入/流动资产 } \\
\text { 期末总额 }\end{array}$ \\
\hline & 总资产报酬率 & X8 & $\begin{array}{l}\text { （利润总额+利息支 } \\
\text { 出）/平均资产总额 }\end{array}$ \\
\hline & $\begin{array}{c}\text { 营业收入增长 } \\
\text { 率 }\end{array}$ & X9 & $\begin{array}{c}\text { 本年营业收入/上年 } \\
\text { 营业收入总额 }\end{array}$ \\
\hline & 资本累积率 & X10 & $\begin{array}{c}\text { 本年所有者权益增 } \\
\text { 长额/年初所有者权 } \\
\text { 益总额 }\end{array}$ \\
\hline \multirow{4}{*}{$\begin{array}{l}\text { 解 } \\
\text { 释 } \\
\text { 变 } \\
\text { 量 }\end{array}$} & 当期政府补助 & GOV & $\begin{array}{c}\text { 当期政府补助金额 } \\
\text { 的自然对数 }\end{array}$ \\
\hline & $\begin{array}{c}\text { 上一年的政府 } \\
\text { 补助 }\end{array}$ & $\mathrm{GOV}_{\mathrm{t}-1}$ & $\begin{array}{c}\text { 上一年政府补助金 } \\
\text { 额的自然对数 }\end{array}$ \\
\hline & $\begin{array}{c}\text { 与收益相关的 } \\
\text { 政府补助 }\end{array}$ & GOVsy & $\begin{array}{c}\text { 本期新增各类与收 } \\
\text { 益相关的政府补助 } \\
\text { 之和的自然对数 }\end{array}$ \\
\hline & $\begin{array}{c}\text { 与资产相关的 } \\
\text { 政府补助 }\end{array}$ & GOVzc & $\begin{array}{l}\text { 本期新增各类与资 } \\
\text { 产相关的政府补助 } \\
\text { 之和的自然对数 }\end{array}$ \\
\hline \multirow{3}{*}{$\begin{array}{l}\text { 控 } \\
\text { 制 } \\
\text { 变 } \\
\text { 量 }\end{array}$} & 产权性质 & OWN & $\begin{array}{c}\text { 国有企业赋值为 } 1 \text {, } \\
\text { 否则为 } 0\end{array}$ \\
\hline & 企业规模 & SIZE & $\begin{array}{c}\text { 年末资产总额的自 } \\
\text { 然对数 }\end{array}$ \\
\hline & 资产负债率 & LEV & 负债总额/资产总额 \\
\hline
\end{tabular}

\section{3 模型构建}

本文运用回归分析法来检验涉农企业政府补助 与公司绩效综合指标的相关性, 建立回归模型, 如下:

$$
\begin{gathered}
Y=\alpha_{0}+\alpha_{1} G O V+\alpha_{2} O W N+\alpha_{3} S I Z E+\alpha_{4} Y E A R+ \\
\alpha_{5} L E V+\varepsilon \\
Y=\alpha_{0}+\alpha_{1} G O V_{t-1}+\alpha_{2} O W N+\alpha_{3} S I Z E+ \\
\alpha_{4} Y E A R+\alpha_{5} L E V+\varepsilon \\
Y=\alpha_{0}+\alpha_{1} G O V \text { sy }+\alpha_{2} O W N+\alpha_{3} S I Z E+ \\
\alpha_{4} Y E A R+\alpha_{5} L E V+\varepsilon
\end{gathered}
$$

$$
\begin{array}{r}
Y=\alpha_{0}+\alpha_{1} G O V \mathrm{zc}+\alpha_{2} O W N+\alpha_{3} S I Z E+ \\
\alpha_{4} Y E A R+\alpha_{5} L E V+\varepsilon
\end{array}
$$

其中, a 0 为常数项; $a 1-a 5$ 是各自的回归系

\begin{tabular}{|c|c|c|}
\hline \multicolumn{2}{|c|}{ KMO 取样适切性量数 } & 0.637 \\
\hline \multirow{3}{*}{ 巴特利特球形度检验 } & 近似卡方 & 1193.826 \\
\hline & 自由度 & 45 \\
\hline & 显著性 & 0.000 \\
\hline
\end{tabular}
数, $\varepsilon$ 是随机误差项。

\section{5. 实证分析}

\section{1 因子分析法计算企业绩效}

因子分析是对每一年的企业绩效因子进行分别 处理, 因文章篇幅有限, 本文主要以 2019 年数据为 例进行说明。

\section{表 $2 \quad \mathrm{KM} 0$ 检验和巴特利特球形检验}

由表 2 的实证结果可知: KM0值是 $0.637>0.50$, 近似卡方是 1193.826 , 自由度 $(\mathrm{df})$ 是 45 , 显著性 水平为 0.000 , 说明 10 个样本数据间效度结构好, 相关性高，适合做因子分析。

\section{表 3 总方差解释}

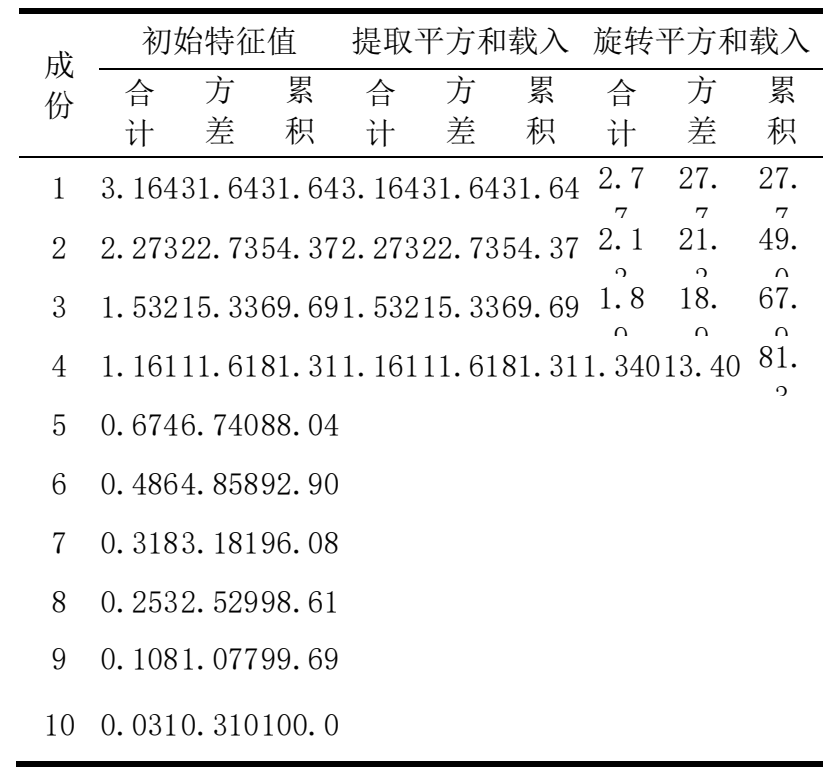

由表 3 的结果可知: 本文提取了特征值大于 1 的 4 个主成分, 其方差贡献率分别为 $27.677 \% 、 21.297 \%$ 、 18. $927 \%$ 和 $13.404 \%$, 特征值分别为 $3.164 、 2.273$ 、 1.532 和 1.161 , 累计贡献率为 $81.305 \%$, 大于临界 值 $70 \%$ ，说明本文选取的四个主成分可以反映 10 个 原始指标的 $81.305 \%$ 的信息。

\section{表 4 成分得分系数矩阵}

\begin{tabular}{ccccc}
\hline \multirow{2}{*}{ 指标名称 } & \multicolumn{5}{c}{ 成份 } \\
\cline { 2 - 5 } & $\mathrm{F} 1$ & $\mathrm{~F} 2$ & $\mathrm{~F} 3$ & $\mathrm{~F} 4$ \\
\hline 现金比率 & 0.353 & 0.028 & -0.042 & 0.010 \\
\hline
\end{tabular}




\begin{tabular}{ccccc}
\hline 流动比率 & 0.367 & 0.042 & -0.051 & 0.010 \\
速动比率 & 0.345 & 0.068 & -0.041 & -0.032 \\
毛利率 & -0.051 & -0.218 & 0.421 & -0.075 \\
每股收益 & -0.069 & 0.000 & 0.461 & -0.052 \\
$\begin{array}{c}\text { 总资产周 } \\
\text { 转率 }\end{array}$ & 0.068 & 0.484 & 0.008 & -0.112 \\
$\begin{array}{c}\text { 流动资产 } \\
\text { 周转率 } \\
\text { 总资产报 }\end{array}$ & 0.022 & 0.443 & -0.011 & -0.013 \\
$\begin{array}{c}\text { 酬率 } \\
\text { 营业收入 } \\
\text { 增长率 }\end{array}$ & 0.004 & 0.149 & 0.401 & 0.044 \\
资本累积 & 0.046 & -0.080 & -0.085 & 0.647 \\
率 & 0.054 & 0.000 & 0.593 \\
\hline
\end{tabular}

根据表 4 中各指标在因子上的载荷乘以指标值, 得出各因子得分, 最后将表 2 中各因子的方差贡献率 占总方差贡献率的比率作为权重, 得出涉农企业绩效 的总得分, 如下式:

$$
\begin{aligned}
F 1= & 0.353 X 1+0.367 X 2+0.345 X 3-0.051 X 4- \\
& 0.069 X 5+0.068 X 6+0.022 X 7+0.004 X 8- \\
& 0.061 X 9+0.046 X 10 \\
F 2= & 0.028 X 1+0.042 X 2+0.068 X 3-0.218 X 4+ \\
& 0.000 X 5+0.484 X 6+0.443 X 7+0.149 X 8- \\
& 0.080 X 9-0.054 X 10 \\
& F 3=-0.042 X 1-0.051 X 2-0.0415 X 3+ \\
& 0.421 X 4+0.461 X 5+0.008 X 6-0.011 X 7+ \\
0.401 X 8-0.085 X 9+0.000 X 10 & (7) \\
F 4= & 0.010 X 1+0.010 X 2-0.032 X 3-0.075 X 4- \\
& 0.052 X 5-0.112 X 6-0.013 X 7+0.044 X 8+ \\
& 0.647 X 9+0.593 X 1
\end{aligned}
$$

\begin{tabular}{|c|c|c|c|c|}
\hline & $\mathrm{N}$ & $\begin{array}{cc}\text { 最小 } & \text { 最大 } \\
\text { 值 } & \text { 值 } \\
\end{array}$ & $\begin{array}{l}\text { 平均 } \\
\text { 数 }\end{array}$ & $\begin{array}{l}\text { 标准 } \\
\text { 差 }\end{array}$ \\
\hline 企业绩效（Y） & 905 & -2.8064 .018 & -0.000 & 0.559 \\
\hline 政府补助（GOV） & 905 & 0.00020 .779 & 16.304 & 4.299 \\
\hline $\begin{array}{c}\text { 上一年的政府补助 } \\
\left(G O V_{t-1}\right)\end{array}$ & 905 & 0.00020 .779 & 16.033 & 32.843 \\
\hline $\begin{array}{c}\text { 与收益相关的政府补助 } \\
\text { (GOVsy) }\end{array}$ & 905 & 0.00020 .70 & 15.937 & 72.529 \\
\hline $\begin{array}{c}\text { 与资产相关的政府补助 } \\
(\mathrm{GOVzc})\end{array}$ & 905 & 0.00019 .595 & 12.237 & 75.852 \\
\hline 产权性质（OWN） & 905 & $0.000 \quad 1.000$ & 0.376 & 0.485 \\
\hline 资产规模 (SIZE) & 905 & 19. 28926.411 & 22.142 & 21.134 \\
\hline
\end{tabular}

其中, 上述 10 个指标为经过标准化处理后的标 准变量。最后根据各主成分的方差贡献率, 并对权重 进行归一化处理后计算出企业绩效综合指标 $\mathrm{Y}$ :

$$
Y=0.34041 F 1+0.26194 F 2+0.23279 F 3+
$$$$
0.16486 F 4
$$

\section{2 回归分析}

表 5 政府补助与财务绩效的描述性统计分析

\begin{tabular}{|c|c|c|c|c|c|c|c|c|}
\hline & Y & GOV & $\begin{array}{c}\text { GOVt } \\
-1\end{array}$ & $\begin{array}{c}\text { GOVs } \\
\mathrm{y}\end{array}$ & $\begin{array}{c}\mathrm{GOVZ} \\
\mathrm{c}\end{array}$ & OWN & SIZE & LEV \\
\hline Y & 1 & & & & & & & \\
\hline GOV & $\begin{array}{c}0.43 \\
6 * *\end{array}$ & 1 & & & & & & \\
\hline $\begin{array}{c}\text { GOVt } \\
-1\end{array}$ & $\begin{array}{c}0.48 \\
5 * *\end{array}$ & $\begin{array}{c}0.85 \\
5 * *\end{array}$ & 1 & & & & & \\
\hline $\begin{array}{c}\text { GOVs } \\
y\end{array}$ & $\begin{array}{l}-0.5 \\
16 * *\end{array}$ & $\begin{array}{l}-0.1 \\
29 * *\end{array}$ & $\begin{array}{l}-0.1 \\
85 * *\end{array}$ & 1 & & & & \\
\hline $\begin{array}{c}\mathrm{GOVS} \\
\mathrm{y}\end{array}$ & $\begin{array}{c}0.53 \\
6 * *\end{array}$ & $\begin{array}{c}0.55 \\
1 * *\end{array}$ & $\begin{array}{c}0.58 \\
5 * *\end{array}$ & $\begin{array}{l}-0.3 \\
24 * *\end{array}$ & 1 & & & \\
\hline OWN & $\begin{array}{c}-0.0 \\
56\end{array}$ & $\begin{array}{c}-0.0 \\
15\end{array}$ & $\begin{array}{c}-0.0 \\
57\end{array}$ & $\begin{array}{c}0.06 \\
4\end{array}$ & $\begin{array}{c}-0.0 \\
10\end{array}$ & 1 & & \\
\hline SIZE & $\begin{array}{c}0.09 \\
9 * *\end{array}$ & $\begin{array}{c}0.06 \\
6 *\end{array}$ & $\begin{array}{c}0.02 \\
7\end{array}$ & $\begin{array}{c}-0.0 \\
21\end{array}$ & $\begin{array}{c}0.09 \\
9 * *\end{array}$ & $\begin{array}{c}0.17 \\
3 * *\end{array}$ & 1 & \\
\hline LEV & $\begin{array}{c}-0.0 \\
47\end{array}$ & $\begin{array}{c}0.04 \\
8\end{array}$ & $\begin{array}{c}0.03 \\
5\end{array}$ & $\begin{array}{c}0.02 \\
8\end{array}$ & $\begin{array}{c}0.00 \\
6\end{array}$ & $\begin{array}{c}0.13 \\
2 * *\end{array}$ & $\begin{array}{c}0.35 \\
3 * *\end{array}$ & 1 \\
\hline
\end{tabular}

$\begin{array}{lllllll}\text { 资产负债率 (LEV) } & 905 & 0.028 & 0.980 & 0.381 & 0.181\end{array}$

由表 5 可知, 涉农上市企业的综合企业绩效Y最 大值 4.018, 最小值-2.806, 行业间的极值之差较大, 说明涉农上市企业的企业绩效差距较大； 5 年来均值 -0.00001 , 说明我国涉农上市企业绩效水平较低, 经 营能力较差。政府补助最小值 0 , 最大值 20.779 , 平 均数在 16.304 。与收益相关的政府补助和与资产相 关的政府补助, 二者最小值都为 0 , 最大值分别为 20.705 和 19.596 , 平均值分别为 15.937 和 12.237 , 两者标准差分别为 2.529 和 5.852, 说明政府在运用 两种补贴方式时所持有的态度是不一的。

\section{表 6 Person 相关性分析}

注: $* *$ 表示在 $\mathrm{p}<0.01$ 情况下显著相关, $*$ 表示在 $\mathrm{p}<0.05$ 情况下 显著相关。

从表 6 可以看出, 企业绩效与政府补助、上一年 的政府补助、与收益相关的政府补助、与资产相关的 政府补助、产权性质、企业规模、资产负债率的系数 分别为 $0.436 、 0.485 、-0.516 、 0.536 、-0.056 、 0.099$ 、 -0.047 。

\section{表 7 政府补助与财务绩效的回归分析表}

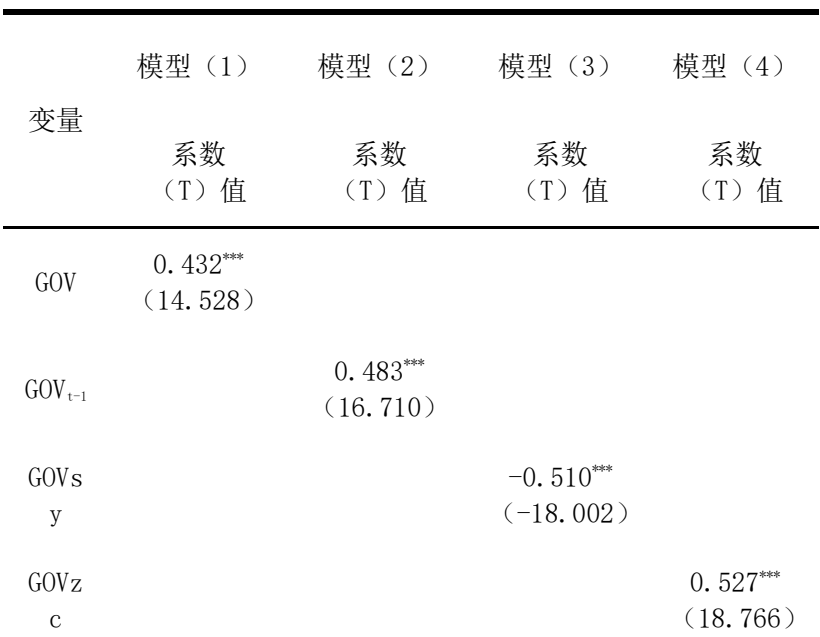




\begin{tabular}{|c|c|c|c|c|}
\hline OWN & $\begin{array}{c}-0.056^{*} \\
(-1.853)\end{array}$ & $\begin{array}{c}-0.037 \\
(-1.243)\end{array}$ & $\begin{array}{l}-0.044^{*} \\
(-1.517)\end{array}$ & $\begin{array}{l}-0.055^{*} \\
(-1.931)\end{array}$ \\
\hline SIZE & $\begin{array}{l}0.115^{* * * *} \\
(3.597)\end{array}$ & $\begin{array}{l}0.129^{* * * *} \\
(4.145)\end{array}$ & $\begin{array}{l}0.120^{\text {***** }} \\
(3.390)\end{array}$ & $\begin{array}{l}0.081^{* * * *} \\
(2.682)\end{array}$ \\
\hline LEV & $\begin{array}{l}-0.101^{* * * *} \\
(-3.184)\end{array}$ & $\begin{array}{l}-0.105^{\text {now }} \\
(-3.398)\end{array}$ & $\begin{array}{l}-0.069^{* *} \\
(-2.287)\end{array}$ & $\begin{array}{l}-0.072^{* *} \\
(-2.390)\end{array}$ \\
\hline $\mathrm{R}^{2}$ & 0.208 & 0.254 & 0.281 & 0.297 \\
\hline $\begin{array}{l}\text { 调整 } \\
\text { 后的 } \\
\mathrm{R}^{2}\end{array}$ & 0.204 & 0.250 & 0.278 & 0.294 \\
\hline $\mathrm{F}$ 值 & 59. 002 & 76. 420 & 87. 887 & 95.069 \\
\hline Sig. & $0.000^{b}$ & $0.000^{b}$ & $0.000^{b}$ & $0.000^{b}$ \\
\hline
\end{tabular}

由表 7 可知, 模型 1 中, 政府补助与企业财务绩 效得分的系数是 0.432 , 在 $1 \%$ 水平上显著正相关。模 型 2 中, 政府补助与滞后一期的企业财务绩效系数是 0. 483, 在 $1 \%$ 水平上显著正相关。模型 3 中, 收益性 的政府补助与企业财务绩效系数是 -0.510 , 在 $1 \%$ 水 平上显著负相关。模型 4 中, 资产性的政府补助与企 业财务绩效系数是 0.527 , 在 $1 \%$ 水平上显著正相关。

对上述实证结果进行分析, 可以看出: 第一, 当 期的政府补助对企业绩效有显著正向影响, 这是因为 政府补助给涉农上市公司带来了资金投入, 增加了抵 御财务风险的能力, 提高了企业的偿债能力, 从而提 高了企业绩效。第二, 政府补助能提高滞后一期的企 业财务绩效, 说明政府补助有助于改善涉农上市企业 未来的财务状况, 这种促进作用是长期有效的。第三, 与收益相关的政府补助对涉农上市企业绩效有消极 作用, 可能因为涉农企业在收到收益性政府补助, 容 易产生短期行为。第四, 与资产相关的政府补助对涉 农上市企业绩效有积极作用, 是因为资产性政府补助 计入递延收益科目，在以后的年度分期计入当期损益， 从而保证资金在企业建设的规范性和持续性, 因此可 以提高企业财务绩效。

\section{6. 结论与建议}

本文得出如下结论: 假设 1 成立, 当期的政府补 助对企业财务绩效有影响, 呈现显著正相关关系。假 设 2 成立, 通过滞后一期的企业绩效与当期的政府补 助对比, 发现涉农上市公司政府补助有利于提升滞后 一期的财务绩效水平。假设 3 不成立, 与收益相关的 政府补助对涉农上市企业财务绩效有消极作用。假设 4 成立, 与资产相关的政府补助对涉农上市企业财务 绩效有积极作用。

建议: 从政府角度, 第一, 继续加大政府补助的 扶持力度。鉴于政府补助对涉农企业财务绩效的正向 影响作用, 政府一方面应该加大政府补助的力度, 让 涉农业企业获得更多好处; 另一方面, 政府应该扩大 政府补助的范围, 确保政府补助覆盖涉农企业生产经 营的各个环节, 使更多的涉农企业受益。第二, 调整
政府补助的结构。通过实证结果，发现资产性政府补 助更能对企业绩效产生正面影响，而与收益相关的政 府补助对涉农上市企业绩效有消极作用。因此，政府 应调整补助结构, 增加资产性补贴, 减少收益性补助, 发挥好每一笔补助的作用。可以根据市场需要, 将补 助资金倾斜于科技创新、绿色生态产品、引进高科技 知识型人才等资产性方面, 契合涉农上市公司的发展 方向, 从提高涉农上市公司的企业绩效, 促进了涉农 上市公司的长远发展。从涉农企业角度来说, 企业应 强化管理、提高决策水平。政府补助对于企业来说, 是生产经营活动中获取的外部资源, 这并不是决定企 业未来可持续发展的关键因素, 企业应当不断学习, 完善公司治理机制、提高决策水平、提升企业运行效 率, 合理利用政府补助, 借助政府良好的扶持政策和 外部发展环境, 实现资源的最优配置, 持续提升公司 绩效和综合素质, 促进公司整体价值的提升, 这才能 为企业的可持续发展提供坚实的保障。

\section{REFERENCES}

[1] Bernini C,Pellegrini G.How are growth and productivity in private firms affected by public subsidy? Evidence from a regional policy [J].Regional Science \& Urban Economics, 2011, 41(3): 253-65.

[2] Guth M,Majchrzak A.resource conditions and subsidies for public goods in the eu[J].proceedings of the International Conference "economic Science for Rural Development”.2017,3(6):23-47.

[3] Chai Yuan. Government Subsidies, Enterprise Innovation Input and Enterprise Performance_— Research on the Mediating Effect Based on Innovation Input[J]. Chinese Market, 2018(28): 7-11.

[4] Attia Mar,Lassoued N,Attia A.Political costs and earnings management:Evidence from Tunisia [J].Journal of Accounting in Emerging Economies,2016,6(4):388-407.

[5] Bu Danlu, Di Lingyu. Governance environment, equity investment and government subsidies[J]. Financial Research, 2017, (10): 193-206.

[6] Tundis E,Gabriele R,Zaninotto E.Investigating the effectiveness of public subsidies to hotels: Evidence from an Alpine region[J].Tourism Management Perspectives,2017,23:8-18.

[7] Zhang Huiming,Li Lianshui,Zhou Dequn,et al.Political connections, government subsidies and firm financial performance:Evidence from renewable energy manufacturing in $\mathrm{China}[\mathrm{J}]$. Renewable Energy,2014,63(Supplement C): 330-336.

[8] Dizon-Ross R,Dupas P,Robinson J.Governance and 
the effectiveness of public health subsidies:Evidence from Ghana,Kenya and Uganda[J].Journal of Public Economics,2017,156:150-169.

[10] Yang Ye,Wang Peng,Li Yihong.Research on the Impact of Financial Subsidies on Enterprise R\&D Investment and Performance-Empirical Evidence from Listed Companies on China's Growth Enterprise Market[J].Finance and Economics,2015,(1):24-31.

[11] Wang Xinhong, Nie Yaqian.Government subsidies, $\mathrm{R} \& \mathrm{D}$ investment and corporate performance[J].
Accounting Communications, 2019,(03),63-67.

[12]Jing Manshi, Yin Xianan.The impact of government subsidies and R\&D investment on corporate performance-Based on different industry perspectives $[\mathrm{J}]$.Accounting Research,2018,(09):61-65.

[13] Qin Li,Ding Fangzheng.Governance environment, government subsidies and company performance - Based on the empirical data of listed companies in the power industry[J]. Accounting Communications,2019(27):61-64 